\title{
Overexpressed vs mutated Kras in murine fibroblasts: a molecular phenotyping study
}

\author{
M Horsch', CV Recktenwald ${ }^{2}$, S Schädler', M Hrabé de Angelis ${ }^{1,3}$, B Seliger ${ }^{*, 2}$ and J Beckers ${ }^{*, 1,3}$ \\ 'Helmholtz Zentrum München - German Research Center for Environmental Health (GmbH), Institute of Experimental Genetics, Ingolstädter \\ Landstraße I, 85764 Neuherberg, Germany; ${ }^{2}$ Martin-Luther-Universität Halle-Wittenberg, Institut für Medizinische Immunologie, Magdeburger Straße 2, \\ 06112 Halle (Saale), Germany; ${ }^{3}$ Technical University Munich, Center of Life and Food Sciences, Institute of Experimental Genetics, 85354 \\ Weihenstephan, Germany
}

Ras acts in signalling pathways regulating the activity of multiple cellular functions including cell proliferation, differentiation, and apoptosis. Amino-acid exchanges at position 12, 13, or 61 of the Kras gene convert the proto-oncogene into an activated oncogene. Until now, a direct comparison of genome-wide expression profiling studies of Kras overexpression and different Kras mutant forms in a single assay system has not been carried out. In our study, we focused on the direct comparison of global gene expression effects caused by mutations in codon 12 or 13 of the Kras gene and Kras overexpression in murine fibroblasts. We determined Kras cellular mRNA, Ras protein and activated Ras protein levels. Further, we compared our data to the proteome analysis of the same transfected cell lines. Both overexpression and mutations of Kras lead to common altered gene expression patterns. Only two genes, Lox and Coll al, were reversely regulated in the Kras transfectants. They may contribute to the higher aggressiveness of the Kras codon 12 mutation in tumour progression. The functional annotation of differentially expressed genes revealed a high frequency of proteins involved in tumour growth and angiogenesis. These data further support the important role of these genes in tumourassociated angiogenesis.

British Journal of Cancer (2009) I 00, 656-662. doi:10.1038/sj.bjc.6604882 www.bjcancer.com

Published online 3 February 2009

(c) 2009 Cancer Research UK

Keywords: Kras mutation; Kras overexpression; murine fibroblast cell lines; gene-expression profiling

The Ras gene family (Hras, Nras, Kras4A, and $4 B$ ) encodes small intracellular, membrane-associated proteins, which are regulated by the GDP/GTP cycle. Switching between the active GTP-bound and the inactive GDP-bound state is regulated by GTPaseactivating proteins (Marshall, 1995) and guanine nucleotide exchange factor proteins (Downward, 1996). Activated Ras stimulates a cascade of serine/threonine kinases that control diverse biological processes including cell proliferation, differentiation, or apoptosis. The Kras proto-oncogene becomes oncogenic by single point mutations in codon 12 or 13 , which locks the mutated Kras gene product in the GTP-bound activated state (Barbacid, 1987). These mutant forms of Ras transduce signals that result in oncogenic transformation, angiogenesis, invasion, and metastasis by downstream pathways (Olson and Marais, 2000). Frequently, activated Kras oncogenes were identified in human bladder, lung, breast, and kidney cancer (Fujita et al, 1988; Solana et al, 1992; Yuasa et al, 1994; Orntoft and Wolf, 1998) as well as in carcinoma of the colon (Capon et al, 1983) and in acute myeloid leukaemia (Neubauer et al, 1994). In addition to

*Correspondence: B Seliger; E-mail: barbara.seliger@medizin.uni-halle.de or J Beckers E-mail: beckers@helmholtz-muenchen.de

Received 28 August 2008; revised II December 2008; accepted I5 December 2008; published online 3 February 2009 the Ras mutants, the generation of multiple Kras gene copies has been detected in murine mammary tumours.

Despite the prevalent role of Kras mutations in tumorigenesis, only a few studies have assessed genome-wide transcriptional changes in Kras-transfected cell lines. Transcript expression analyses have been performed comparing normal rat embryo fibroblasts and cells transformed by mutant Hras, Kras, and Nras (Zuber et al, 2000). Neoplastic transformation driven by the mutated Kras oncogene was analysed by expression profiling of rat ovarian epithelial cells (Tchernitsa et al, 2004). Differentially regulated genes in response to an activated mutation in Kras or Hras were analysed in a colon adenoma cell line, employing microarray technology (Roberts et al, 2006). Transcriptome analysis described changes in gene expression levels of embryonic mouse fibroblasts carrying a mutation in codon 12 of Kras (Vasseur et al, 2003). These studies showed that genes regulated by the activated forms of Ras involve cellular processes associated with tumorigenesis.

Clinical studies have suggested that tumour cells carrying Kras codon 13 mutations are less aggressive than those with codon 12 mutations (Bazan et al, 2002). Different levels of aggressiveness in the transforming phenotype induced by mutations in Kras codon 12 or 13 and the overexpression of the Kras proto-oncogene in transfected NIH3T3 cells were also described (Guerrero et al, 2000). These results suggest that despite many similarities in 
their oncogenic capacity, the different mutant forms and Ras overexpression may activate also distinct downstream targets that are responsible for the different oncogenic capacities.

So far, a direct comparison of genome-wide transcript profiles of different Kras mutant forms and Kras overexpression in a single assay system has not been performed. Because of these reasons we used genome-wide expression profiling analysis to investigate differences among samples of murine fibroblasts carrying Kras codon 12 or 13 mutations and cells that constitutively overexpress the wild-type (wt) Kras gene. In wt Kras, the codons at position 12 and 13 encode two adjacent glycines located in the GDP/GTPbinding site of Ras. The G12V and G13D mutations lead to the constitutive binding of GTP and as a consequence to a permanent activation of the signal transduction cascade. We analysed Kras NIH3T3 transfectants carrying mutations at codon $12\left(\mathrm{Kras}^{\mathrm{G} 12 \mathrm{~V}}\right)$ or $13\left(\operatorname{Kras}^{\mathrm{G} 13 \mathrm{D}}\right)$ or overexpress wt Kras $\left(\operatorname{Kras}^{\mathrm{Oe}}\right)$. The non-transfected parental (NIH3T3) and mock-transfected cells (Kras $\left.{ }^{\text {mock }}\right)$ served as controls. The total amounts of Kras cellular RNA, Ras, and active Ras proteins were measured in all cell lines. Hierarchical clustering of differentially expressed genes was used to compare the gene expression patterns of the distinct transfected cell lines. Furthermore, we analysed the functional classification of the regulated genes and their role in distinct carcinogenic processes.

\section{MATERIALS AND METHODS}

\section{Kras-transfected cell lines}

Wildtype and mutated Kras genes were amplified by RT-PCR from human cell lines and cloned into the pIREShyg expression vector of murine NIH3T3 fibroblast as recently described (Recktenwald et al, 2007). Total RNA from transfecants and non-transfected cell lines was obtained according to the manufacturer's protocols using RNeasy Midi kits (Qiagen, Hilden, Germany). The RNA concentration was calculated from $\mathrm{OD}_{260 / 280}$ readings and $2 \mu \mathrm{g}$ RNA aliquots were run on formaldehyde agarose gels to check for RNA integrity.

\section{DNA microarrays}

Glass cDNA chips were produced as recently described (Horsch et al, 2008). A full description of the approximate 21000 probes on the microarray is available in the GEO database under GPL3697. The expression data of Kras-transfected NIH3T3 cell lines have been submitted to the GEO database (GSE8372).

Four independent dual colour hybridisations including two dye swap experiments were performed with RNA from each of the four transfected cell lines (in total $n=16$ ) using non-transfected cells as reference. All experiments were performed according to a modified TIGR protocol (Horsch et al, 2008). Slides were scanned with a GenePix 4000A microarray scanner and the images analysed with the GenePix Pro6.1 image processing software (Molecular Devices, CA, USA).

\section{Analysis of gene expression levels}

Statistical analyses were performed with TIGR Microarray Data Analysis System (TM4) including MIDĀS (Microarray Data Analysis System; Quackenbush, 2002) for normalisation and SAM (significant analysis of microarrays; Tusher et al, 2001) for identification of genes with significant differential regulation. Cluster analyses were employed using HCL (hierarchical cluster analyses; Eisen et al, 1998).

Expression data were processed (MIDAS) applying a total intensity normalisation, and low-quality array elements were eliminated by several filtering methods, such as background checking for both channels with a signal/noise threshold of 2.0, one bad tolerance policy parameter, and a flip dye consistency check. First, a multiclass SAM analysis for the identification of significant gene regulation in $\mathrm{Kras}^{\mathrm{oe}}$, $\mathrm{Kras}^{\mathrm{G} 12 \mathrm{~V}}$, and $\mathrm{Kras}^{\mathrm{G} 13 \mathrm{D}}$ transfectants was performed. Therefore, three groups of experiments were specified: Four chip hybridisations of $\mathrm{Kras}^{\mathrm{oe}}$-, $\mathrm{Kras}^{\mathrm{G} 12 \mathrm{~V}_{-}}$, and $\mathrm{Kras}^{\mathrm{G} 13 \mathrm{D}^{-}}$-transfected cell lines built a separate group. Genes were considered as significant if they were differentially regulated in at least two of the three specified groups. Second, significantly regulated genes in the Kras ${ }^{\text {mock }}$ transfectants were identified by one class analysis. The percentage of genes identified by chance is the false discovery rate (FDR), which was estimated by calculating 1000 permutations. For hierarchical clustering of expression profiles, the average-linkage method was applied. As distance metric the Euclidean distance was chosen.

\section{In silico pathway analysis}

For in silico analysis of differentially expressed genes, EASE, a module of the DAVID database (Dennis et al, 2003) assigning genes to gene ontology (GO) functional categories, was employed. EASE analysis, including a Bonferroni multiplicity correlation, evaluated the set of differentially expressed genes for overrepresentation of two categories of GO terms: biological processes and molecular functions.

\section{Real-time quantitative (qRT) PCR}

Ten differentially expressed genes (Col6a1, Fapb5, Ftl1, H3f3b, Lox, Prss23, S100a11, Sparc, Sqstm1, and Vim) as well as the expression levels of Kras were assessed by qRT - PCR performed in a 7700 SDS thermal cycler using the SYBR Green I system (Applied Biosystems, Darmstadt, Germany). Two target-specific primer pairs were designed for each selected gene using OligoPerfect ${ }^{\mathrm{TM}}$ Designer (Invitrogen, Karlsruhe, Germany) and purchased from Sigma (Taufkirchen, Germany). Duplicate crossing points per marker were averaged per independent experiment for both primer pairs ( $n=16$, including two cDNA dilutions). Values were normalised to levels of $\beta$-actin.

\section{Analysis of total and activated Ras expression levels}

Expression levels of active GTP-bound Ras as well as total Ras were determined as described previously (Recktenwald et al, 2007). Activated Ras molecules were isolated with a selective pull-down assay with glutathione S-transferase-Raf1-Ras-binding domain fusion protein (GST-Raf1-RBD) using the EZ-Detect ${ }^{\mathrm{TM}}$-Ras-Activation Kit (Perbio, Bonn, Germany). Cells were harvested, lysed, and incubated with GST-Raf1-RBD and one swell gel glutathione disc. After three washing steps with lysis buffer, GTP-bound Ras was eluted with SDS sample buffer (Laemmli UK 1970) and boiled. Equal protein amounts were separated on $12 \%$ SDS polyacrlyamide gels and transferred onto nitro cellulose membranes. Ras molecules were visualised by incubation of the membranes with anti-Ras primary antibody followed by incubating with a horse-raddish peroxidasecoupled antimouse secondary antibody. The complexes were detected using the enhanced chemiluminescence Kit (Perbio).

\section{RESULTS}

\section{Morphological changes of the Kras transfectants}

As recently described (Recktenwald et al, 2007), the morphology of Kras transfectants was characterised by a more spindle-like shape and appeared less flat as parental and mock control cells. Furthermore, the Kras transfectants exhibit long cell extensions suggesting the development of filo- and/or lamellipodiae. These morphological changes are most prominent in Kras mutants and 
weaker in the $\mathrm{Kras}^{\mathrm{oe}}$ transfectants. In addition, all Kras transfectants show an increased cell growth as indicated by reduced doubling times (data not shown).

\section{Kras transcript and protein expression levels}

We measured the levels of Kras gene expression in all cell lines investigated by qRT - PCR. No changes in the total amount of Kras in Kras ${ }^{\text {mock}}, \mathrm{Kras}^{\mathrm{G} 12 \mathrm{~V}}$, and Kras ${ }^{\mathrm{G} 13 \mathrm{D}}$ cell lines compared with the non-transfected cell lines were identified (Figure 1A). The overexpression of Kras was only detected in $\mathrm{Kras}^{\mathrm{oe}}$ transfectants. Additionally, for the determination of the Ras protein expression, the activation status as well as the total cellular Ras expression of the different Ras oncoproteins was analysed by western blot analysis. Kras ${ }^{\mathrm{G} 12 \mathrm{~V}}$ and Kras ${ }^{\mathrm{G} 13 \mathrm{D}}$ cells showed similar increased levels of total cellular Ras proteins when compared with the parental- (NIH3T3) and mock-transfected cell lines (Figure 1B). Furthermore, activated GTP-bound Ras was only detectable in these two cell lines (Figure 1B). Although the level of Kras transcript was not influenced by the mutations, the protein levels and its activity were increased in Kras ${ }^{\mathrm{G} 12 \mathrm{~V}}$ and Kras ${ }^{\mathrm{G}}{ }^{3 \mathrm{D}}$ cells. Kras overexpression on transcript level had no influence on cellular protein or active Ras protein level.

\section{Comparative analysis of gene expression patterns}

In this study, a comparison of global gene expression effects caused by mutations in codon $12\left(\mathrm{Kras}^{\mathrm{G} 12 \mathrm{~V}}\right)$ or $13\left(\mathrm{Kras}^{\mathrm{G} 13 \mathrm{D}}\right)$ of the Kras proto-oncogene and Kras overexpression $\left(\mathrm{Kras}^{\mathrm{oe}}\right)$ in murine fibroblasts was performed. A multiclass SAM analysis identified 61 genes significantly regulated in at least two out of the three Kras ${ }^{\text {oe }}$, Kras ${ }^{\mathrm{G} 12 \mathrm{~V}}$, and Kras ${ }^{\mathrm{G} 13 \mathrm{D}}$ transfectants compared with non-transfected parental cells. Significance was assigned using an FDR threshold of $<0.05$ in conjunction with a ratio threshold of $>1.5$. In all, 17 out of 34 genes significantly regulated in Kras ${ }^{\text {mock }}$ transfectants were also identified as differentially expressed in the three experimental cell lines (Kras ${ }^{\mathrm{G} 12 \mathrm{~V}}$, Kras ${ }^{\mathrm{G} 13 \mathrm{D}}$, and $\mathrm{Kras}^{\mathrm{oe}}$ ).

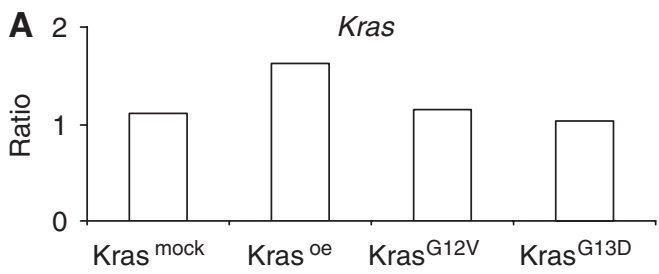

B NIH3T3 Kras ${ }^{\text {mock }}$ Kras $^{\text {oe }}$ Kras $^{\text {G12V }}$ Kras $^{\text {G13D }}$

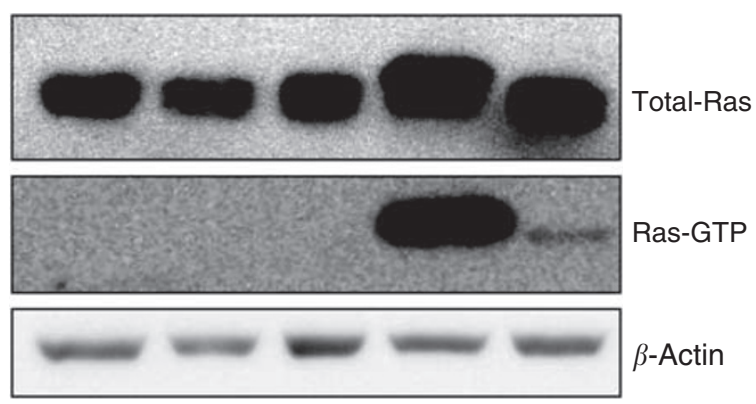

Figure I Kras transcript and protein expression levels. (A) Kras expression levels were measured by qRT-PCR. The results are given as the linear ratio of expression levels relative to the expression level of Kras expression in the non-transfected $\mathrm{NIH} 3 \mathrm{~T} 3$ cells. Numbers on the $Y$ axis show the fold changes of gene expression levels. (B) Quantification of total Ras and activated Ras molecules by western blotting. $\beta$-actin served as loading control.
On the basis of the rational that the altered expression level of these 17 genes was most likely caused by the transfection procedure itself, these genes were excluded from the subsequent hierarchical clustering and GO term analyses.

Hierarchical cluster analysis was applied on the remaining 44 genes differentially expressed in at least two out of three experimental Kras transfectants, but not in the Kras ${ }^{\text {mock }}$ cell line. The cluster algorithm classified the selected genes into three groups based on the similarities in expression patterns across the transfectants (Figure 2): the first group comprises upregulated genes (Figure 2, indicated as ' $\mathrm{A}$ '), the second group comprises the downregulated genes (Figure 2, indicated as ' $B$ ') in the $\mathrm{Kras}^{\mathrm{oe}}{ }_{-}$, $\mathrm{Kras}^{\mathrm{G} 12 \mathrm{~V}}$-, and/or Kras ${ }^{\mathrm{G} 13 \mathrm{D}}$-transfected cell lines. The genes of the subgroup $\mathrm{C}$ were upregulated in $\mathrm{Kras}^{\mathrm{oe}}$, downregulated in
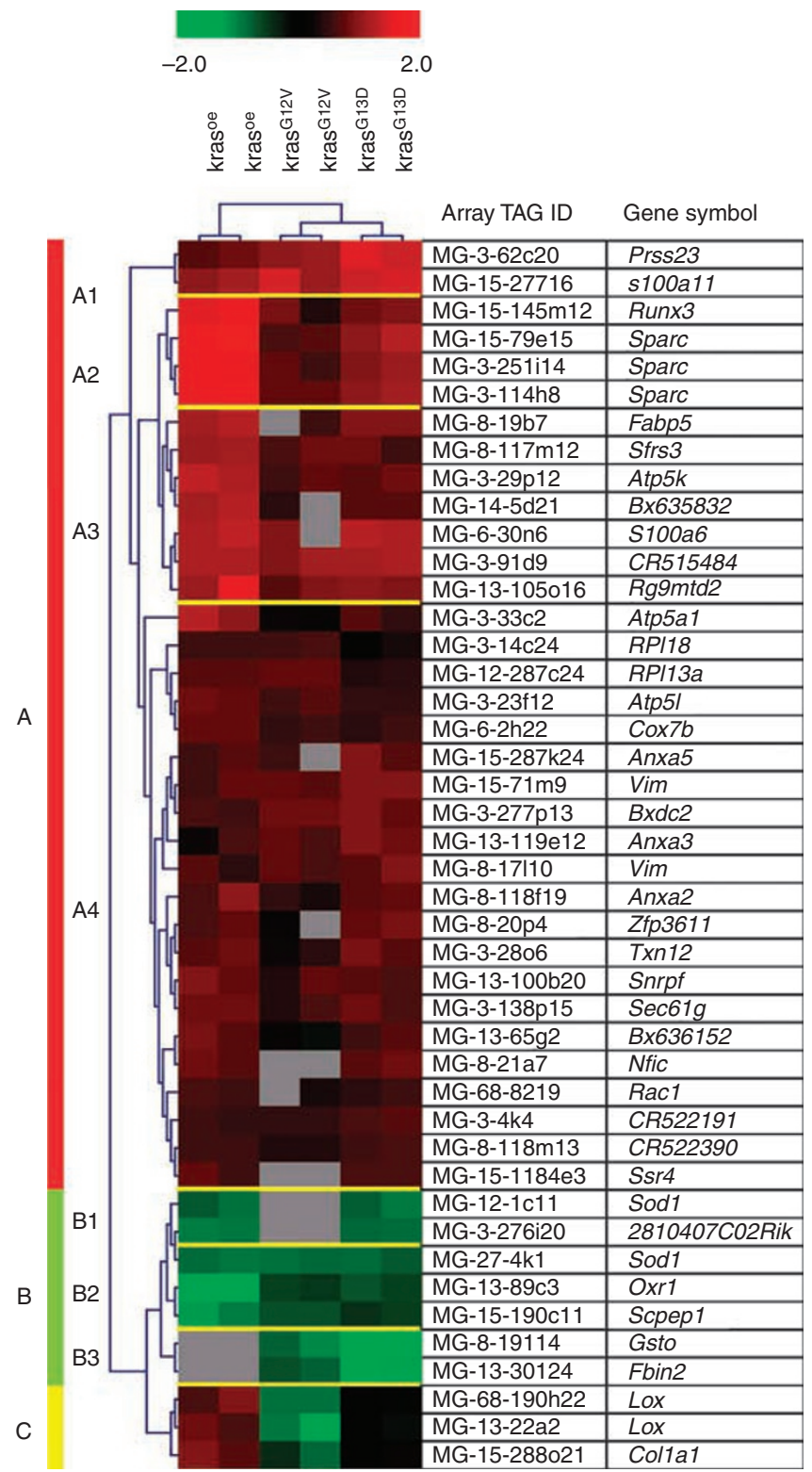

Figure 2 Hierarchical cluster analysis. Hierarchical cluster analysis was performed using gene expression data from 44 probes significantly differentially expressed in at least two out of three transfected NIH3T3 cell lines. For each gene, red indicates higher expression relative to the control and green indicates lower gene expression. Grey boxes represent genes with expression levels below detection limits. Several subgroups of genes with similar expression patterns are colour coded to the left of the heat plots. 
$\mathrm{Kras}^{\mathrm{G} 12 \mathrm{~V}}$, and showed no regulation in Kras ${ }^{\mathrm{G} 13 \mathrm{D}}$ (Figure 2, indicated as ' $\mathrm{C}$ '). For Lox, both non-overlapping sequences represent similar values of transcriptional changes compared with the reference cells. Increased expression levels of 1.8/1.9-fold changes for Lox/Collal were found in $\mathrm{Kras}^{\mathrm{oe}}$. In Kras ${ }^{\mathrm{G} 12 \mathrm{~V}}$, Lox/Col1a1 was downregulated (2.1/1.6-fold changes). Ratios of -1.07 for Lox and 1.13 for Collal in Kras ${ }^{\mathrm{G} 13 \mathrm{D}}$ indicate no significant differences between this transfected cell line and the reference. These data indicate that the overexpression of Kras $\left(\mathrm{Kras}^{\mathrm{oe}}\right)$ influences the regulation of genes similarly to the regulation induced by the mutations in codon 12 or 13 of Kras. Yet, cluster analysis revealed more similarities between gene expression patterns of $\mathrm{Kras}^{\mathrm{G} 12 \mathrm{~V}}$ and $\mathrm{Kras}^{\mathrm{G} 13 \mathrm{D}}$ transfectants (Figure 2) when compared with $\mathrm{Kras}^{\text {oe }}$ cells.

Changes in the expression levels of 10 genes (Col6a1, Fabp5, Ftl1, H3f3b, Lox, Prss23, S100a11, Sparc, Sqstm1, and Vim) identified as regulated in the microarray experiments were validated by qRT - PCR. With the exception of $H 3 f 3 b$, the tendency in terms of up- and downregulation was confirmed in all four cell lines (Figure 3).

\section{Functional classification of regulated genes}

To analyse whether specific functional annotations were overrepresented among the regulated genes, EASE was used to classify the genes for two categories of GO terms: biological processes and molecular functions. The overrepresentation of nine molecular functions was detected (Table 1A): for example, catalytic and structural molecule activity or binding of calcium ions, nucleic acids, lipids, or proteins. GO term analysis of biological processes identified cell growth, development, nucleic acid metabolism, cell proliferation, and protein metabolism as over-represented (Table 1B). Thus, the upregulation of eight calcium-binding proteins suggests that altered intracellular signalling might be
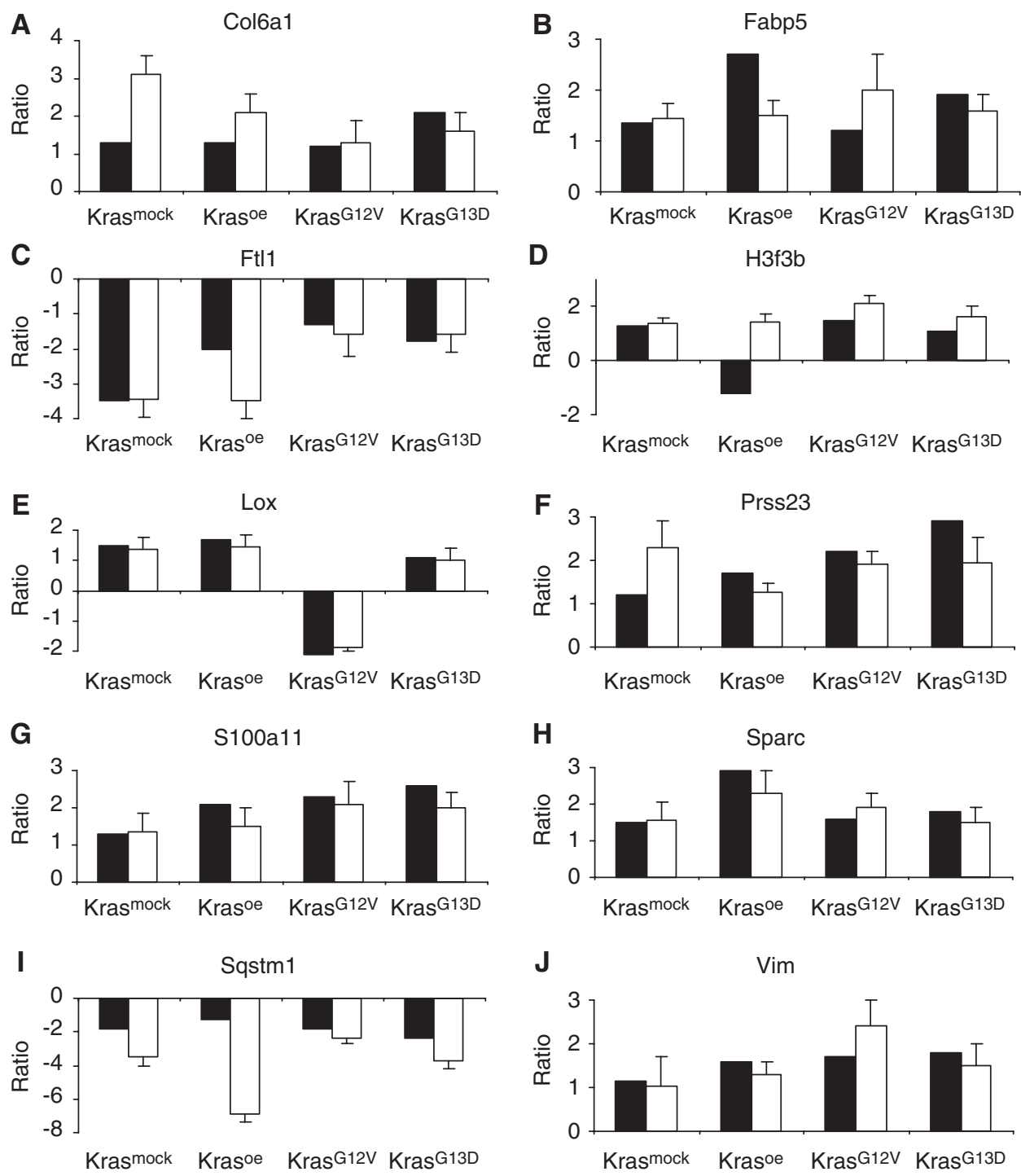

Array

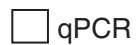

Figure 3 Validation of microarray experiments. qRT-PCR from 10 regulated genes in the four transfected cell lines compared with microarray data. Results are illustrated as ratios of expression relative to the expression of the reference (non-transfected NIH3T3 cells). Black columns represent the mean linear ratio of four microarray experiments, and white columns the mean linear ratios of qRT-PCR. Numbers on the $Y$ axis show the fold changes of gene expression levels. Data represented are : (A) Colbal, (B) Fapb5, (C) Ftll, (D) H3F3b, (E) Lox, (F) Prss23, (G) SI O0a I I, (H) Sparc, (I) Sqstm I, and (J) Vim. 
660

Table I Gene ontology

\begin{tabular}{|c|c|}
\hline GO term & Gene symbol \\
\hline \multicolumn{2}{|l|}{ (A) Molecular functions } \\
\hline Calcium-ion binding & $\begin{array}{l}\text { Anxa2, Anxa3, Anxa5, Fbln2, SIOOAII, SIO0A6, } \\
\text { Sparc, Ssr4 }\end{array}$ \\
\hline Nucleic acid binding & Nfic, RPII 8, Runx3, Sfrs3, Snrpf, Zfp361I \\
\hline Catalytic activity & Anxa3, Atp5al, Cox7b, Lox, Racl, Sodl \\
\hline Transporter activity & Atp5al, Atp5 I, Cox7b, Fabp5, Sec6IG \\
\hline $\begin{array}{l}\text { Structural molecule } \\
\text { activity }\end{array}$ & Collal, Fbln2, Rp/l 3a, Rpl/8, Vim \\
\hline $\begin{array}{l}\text { Enzyme regulator } \\
\text { activity }\end{array}$ & Anxa2, Anxa3, anxa5, S100ab \\
\hline Lipid binding & Anxa2, Anxa3, Anxa5, Fabp5 \\
\hline Oxidoreductase activity & Cox7b, Lox, Sodl \\
\hline Protein binding & SIO0A6, Sparc, Vim \\
\hline \multicolumn{2}{|l|}{ (B) Biological processes } \\
\hline Cell growth & $\begin{array}{l}\text { Atp5al, Atp5 I, Fabp5, Nfic, Racl, Runx3, SlO0al I, } \\
\text { Sl00a6, Sec6l g, Ssr4, Zfp36ll }\end{array}$ \\
\hline Development & $\begin{array}{l}\text { Anxa2, Collal, Cox7b, Fabp5, Racl, Sl00ab, SodI, } \\
\text { Sparc }\end{array}$ \\
\hline Nucleic acid metabolism & Atp5al, Atp5 I, Nfic, Runx3, Sl00al I, Sfrs3, Snrpf \\
\hline Cell proliferation & Nfic, Ras I, Runx3, S100al I, S100ab, Zfp361I \\
\hline Protein metabolism & Lox, Rp//3a, Rp//8, Sec6/g \\
\hline
\end{tabular}

associated with constitutive Kras activation. Additionally, several genes functionally associated with cell growth, proliferation, development, and structural molecule activity indicate pathways involved in Kras-mediated tumour development and metastasis.

\section{DISCUSSION}

In this study, we focused specifically on the direct comparison of the global gene expression effects caused by mutations in codon 12 or 13 of the Kras proto-oncogene and Kras overexpression. In general, the significantly differentially expressed genes followed the same tendency of regulation in the three transfected cell lines. Yet, cluster analysis revealed more similarities between gene expression patterns of $\mathrm{Kras}^{\mathrm{G} 12 \mathrm{~V}}$ and $\mathrm{Kras}^{\mathrm{G} 13 \mathrm{D}}$ transfectants compared with Kras ${ }^{\text {oe }}$ cells. The level of cellular RNA was only elevated in $\mathrm{Kras}^{\mathrm{oe}}$, whereas the amount of activated Ras molecules was increased in Kras ${ }^{\mathrm{G} 12 \mathrm{~V}}$ and $\mathrm{Kras}^{\mathrm{G} 13 \mathrm{D}}$ cells. The differences in transcript expression patterns among the transfectants might be due to the mutation-mediated constitutive activation of Kras. In contrast, the overexpressed form of Kras still can switch from the activated to the non-activated state (Wittinghofer, 1998).

There is clear evidence that the activation of the Raf/MAPK pathway is sufficient for oncogenic transformation mediated by Ras (Ellis and Clark, 2000). The expression of wt and mutant Kras alleles caused constitutive activation of this pathway as indicated by the phosphorylation status of Raf, Erk1, and Erk2 (Recktenwald et al, 2007). Our microarray experiments detected no significant changes in gene expression levels of MAP kinases. However, for the overexpressed genes, Rac1 and Sparc regulatory effects in the MAP kinase pathways has been described (Frost et al, 1997; Kato et al, 2001).

Proteome analysis of the transfected cell lines selected differentially expressed proteins at least 2-fold up- or downregulated compared with NIH3T3 cells (Recktenwald et al, 2007). Up to 52 differentially expressed proteins were detected in the various Kras transfectants. Our expression profiling analysis identified 44 differentially expressed genes in at least two out of three transfectants (Kras ${ }^{\mathrm{oe}}, \mathrm{Kras}^{\mathrm{G} 12 \mathrm{~V}}$, and $\mathrm{Kras}^{\mathrm{G} 13 \mathrm{D}}$ ). In general, the overlapping transcripts and the proteins followed the same tendency of regulation in the different cell lines. Similar regulation in both transcriptome and proteome studies were found for Anxa5, S100a11, and Fapb5 in Kras ${ }^{\mathrm{G} 12 \mathrm{~V}}$-transfectants as well as for Sod1 in $\mathrm{Kras}^{\mathrm{oe}}$. Furthermore, the genes Lox and Colla1, and the protein Hsp86 were reversely regulated between the Kras transfectants. However, a few proteins (eg, Anxa2) showed a reverse regulation compared with their transcripts. This comparison between differentially expressed proteins and transcripts suggests that changes at the protein level were associated in some cases with a corresponding transcriptional regulation.

Several of the significantly regulated genes identified in our study were annotated with cellular functions such as cell growth (eg, Atp5a1, Fabp5, Runx, and S100a6) and cell death (eg, S100a11), angiogenesis (eg, Anxa2 and Zfp36l1), tumorigenesis (eg, Fabp5, Prss23, and Runx), and metastasis (eg, Lox and $S p a r c)$. Genes with very similar functional annotations were also regulated in expression studies of $\mathrm{Kras}^{\mathrm{G} 12 \mathrm{~V}}$-transformed rat embryonic fibroblast (Tchernitsa et al, 2004) in tumours derived from Kras ${ }^{\mathrm{G} 12 \mathrm{~V}}$ mouse embryonic fibroblasts (Vasseur et al, 2005) and in a human colon adenoma cell line constitutive active Kras due to a mutation in codon 12 (Roberts et al, 2006). These data suggest that independent of the cellular system and species background (mouse, rat, or human), the G12V mutation influences the regulation of the same cellular processes.

Potential role of the regulated genes in tumour development and progression were also identified by GO analysis. The genes under the over-represented terms on structural molecular activity, cell growth, and cell proliferation include several genes directly annotated with tumorigenesis. For example, Runx3 was described as a tumour suppressor in gastric carcinogenesis (Peng et al, 2008). Significant overexpression of transcript $Z f p 36 l 1$ was found in lymph node and breast carcinomas (Abba et al, 2007), and increased Fabp5 expression induces metastasis in human prostate carcinomas (Morgan et al, 2008). Through such functional roles of genes differentially expressed by constitutive Kras activation or its overexpression, Kras potentially influence tumour progression.

Angiogenesis is a cellular function whereby solid tumours recruit their own blood supply. In microarray studies, it was hypothesised that fibroblast secrete molecules that both promote and inhibit angiogenesis (Pollina et al, 2008). Lox, Sparc, and Sod1 genes with copper-binding capacity have been associated with angiogenesis (Lane et al, 1994; Juarez et al, 2006; Shieh et al, 2007). Those genes identified in our study to be associated with angiogenesis indicate pathways involved in Kras-mediated tumour development and metastasis.

Different levels of aggressiveness in the transforming phenotype induced by mutations in Kras codons 12 or 13, and the overexpression of the Kras proto-oncogene in transfected tumour cells have been described (Guerrero et al, 2000; Bazan et al, 2002). In our study, activated Ras was stronger increased in Kras ${ }^{\mathrm{G} 12 \mathrm{~V}}$ than Kras $^{\mathrm{G} 13 \mathrm{D}}$ cells suggesting a diminished protein stability of the Kras ${ }^{\text {G13D }}$ oncoprotein. It would be speculated that due to the possible switch from the activated to the non-activated state of overexpressed wt Kras, this overexpression has no influence on the amount of activated Ras molecules. Thus, despite many similarities in their oncogenic capacity the different mutant forms and overexpression of Kras may lead to a modulated activation of downstream targets that are responsible for these distinct oncogenic capacities. For example, the G12V mutation was more prevalent in metastatic human colorectal carcinoma than the codon 13 mutation (Al-Mulla et al, 1998).

The two genes, Lox and Colla1, exhibiting either a reverse or non-regulation in the various transfectants may contribute to the different malignant phenotype. Despite the well-known physiological activity of Lox, its role in oncogenesis is quite controversially discussed. Elevated expression levels of Lox were detected in hypoxic human tumour cells (Erler et al, 2006) and in invasive/ metastatic human breast cancer cell lines (Payne et al, 2005). However, reduced Lox levels were also observed in many cancers 
and cancer-derived cell lines (Csiszar et al, 2002; Kaneda et al, 2004). Additionally, Lox expression could inhibit the transforming activity of the Ras oncogene in NIH3T3 fibroblasts (Min et al, 2007) suggesting a possible role of Lox as tumour suppressor (Di Donato et al, 1997). Paradoxically, Lox expression is associated with both tumour suppression and tumour progression. Its role in tumorigenesis seems dependent on cellular location, cell type, and transformation status (Erler et al, 2006). The lower expression of Lox in the Kras ${ }^{\mathrm{G} 12 \mathrm{~V}}$-induced tumours may contribute to the higher aggressiveness of this mutation. In contrast, the upregulation of Lox in $\mathrm{Kras}^{\mathrm{oe}}$ transfectants could be interpreted as an important inhibitory factor of the transforming activity of Kras.

The downregulation of type I collagen gene (Colla1) is a common feature of Ras transformation (Thomas et al, 2005). However, the overexpression of wt Ras itself is apparently not sufficient to reduce the expression of Colla1 (Slack et al, 1992). Decreased expression levels of Colla1 were identified only in $\mathrm{Kras}^{\mathrm{G} 12 \mathrm{~V}}$ transfectants showing the highest Ras activity. Furthermore, no effects of wt Ras overexpression in rat fibroblasts on Colla1 mRNA level were found (Slack et al, 1992), whereas the gene was upregulated in $\mathrm{Kras}^{\text {oe }}$ cells. We conclude that the overexpression of Col1a1 may suppress the transformed phenotype, whereas the downregulation of Colla1 mediated by the codon 12 Kras mutation contributes to the neoplastic phenotype with the ability of tumour cells to metastasise.

Identification and characterisation of genes differentially regulated by Kras overexpression and different Kras mutant forms should shed light on the understanding of how this oncogene regulates cell transformation and tumorigenesis.

\section{ACKNOWLEDGEMENTS}

We thank Constanze König and Frank Thiele for their excellent technical support in the qRT - PCR experiments. We are grateful to Rashmi Rajendra for her comments on our manuscript. The work was supported by grants from the National genome research network (NGFN 01GR0448 and 01GR0430) to JB and grants from the Deutsche Forschungsgemeinschaft including the SFB432, A6, DFG581-1/2, and the MERCK KGaA to BS.

\section{REFERENCES}

Abba MC, Sun H, Hawkins KA, Drake JA, Hu Y, Nunez MI, Gaddis S, Shi T, Horvath S, Sahin A, Aldaz CM (2007) Breast cancer molecular signatures as determined by SAGE: correlation with lymph node status. Mol Cancer Res 5: $881-890$

Al-Mulla F, Going JJ, Sowden ET, Winter A, Pickford IR, Birnie GD (1998) Heterogeneity of mutant versus wild-type Ki-ras in primary and metastatic colorectal carcinomas, and association of codon-12 valine with early mortality. J Pathol 185: $130-138$

Barbacid M (1987) ras genes. Annu Rev Biochem 56: 779-827

Bazan V, Migliavacca M, Zanna I, Tubiolo C, Grassi N, Latteri MA, La Farina M, Albanese I, Dardanoni G, Salerno S, Tomasino RM, Labianca R, Gebbia N, Russo A (2002) Specific codon $13 \mathrm{~K}$-ras mutations are predictive of clinical outcome in colorectal cancer patients, whereas codon $12 \mathrm{~K}$-ras mutations are associated with mucinous histotype. Ann Oncol 13: 1438-1446

Capon DJ, Seeburg PH, McGrath JP, Hayflick JS, Edman U, Levinson AD, Goeddel DV (1983) Activation of Ki-ras2 gene in human colon and lung carcinomas by two different point mutations. Nature 304: 507-513

Csiszar K, Fong SF, Ujfalusi A, Krawetz SA, Salvati EP, Mackenzie JW, Boyd CD (2002) Somatic mutations of the lysyl oxidase gene on chromosome 5q23.1 in colorectal tumors. Int J Cancer 97: 636-642

Dennis Jr G, Sherman BT, Hosack DA, Yang J, Gao W, Lane HC, Lempicki RA (2003) DAVID: database for annotation, visualization, and integrated discovery. Genome Biol 4: P3

Di Donato A, Lacal JC, Di Duca M, Giampuzzi M, Ghiggeri G, Gusmano R (1997) Micro-injection of recombinant lysyl oxidase blocks oncogenic p21-Ha-Ras and progesterone effects on xenopus laevis oocyte maturation. FEBS Lett 419: 63-68

Downward J (1996) Control of ras activation. Cancer Surv 27: 87-100

Eisen MB, Spellman PT, Brown PO, Botstein D (1998) Cluster analysis and display of genome-wide expression patterns. Proc Natl Acad Sci USA 95: $14863-14868$

Ellis CA, Clark G (2000) The importance of being K-Ras. Cell Signal 12: $425-434$

Erler JT, Bennewith KL, Nicolau M, Dornhofer N, Kong C, Le QT, Chi JT, Jeffrey SS, Giaccia AJ (2006) Lysyl oxidase is essential for hypoxiainduced metastasis. Nature 440: $1222-1226$

Frost JA, Steen H, Shapiro P, Lewis T, Ahn N, Shaw PE, Cobb MH (1997) Cross-cascade activation of ERKs and ternary complex factors by Rho family proteins. EMBO J 16: 6426-6438

Fujita J, Kraus MH, Onoue H, Srivastava SK, Ebi Y, Kitamura Y, Rhim JS (1988) Activated H-ras oncogenes in human kidney tumors. Cancer Res 48: $5251-5255$

Guerrero S, Casanova I, Farre L, Mazo A, Capella G, Mangues R (2000) $\mathrm{K}$-ras codon 12 mutation induces higher level of resistance to apoptosis and predisposition to anchorage-independent growth than codon 13 mutation or proto-oncogene overexpression. Cancer Res 60: 6750-6756
Horsch M, Schädler S, Gailus-Durner V, Fuchs H, Meyer H, de Angelis MH, Beckers J (2008) Systematic gene expression profiling of mouse model series reveals coexpressed genes. Proteomics 8: 1248-1256

Juarez JC, Betancourt Jr O, Pirie-Shepherd SR, Guan X, Price ML, Shaw DE, Mazar AP, Donate F (2006) Copper binding by tetrathiomolybdate attenuates angiogenesis and tumor cell proliferation through the inhibition of superoxide dismutase 1. Clin Cancer Res 12: 4974-4982

Kaneda A, Wakazono K, Tsukamoto T, Watanabe N, Yagi Y, Tatematsu M, Kaminishi M, Sugimura T, Ushijima T (2004) Lysyl oxidase is a tumor suppressor gene inactivated by methylation and loss of heterozygosity in human gastric cancers. Cancer Res 64: 6410-6415

Kato Y, Lewalle JM, Baba Y, Tsukuda M, Sakai N, Baba M, Kobayashi K, Koshika S, Nagashima Y, Frankenne F, Noel A, Foidart JM, Hata RI (2001) Induction of SPARC by VEGF in human vascular endothelial cells. Biochem Biophys Res Commun 287: 422-426

Lane TF, Iruela-Arispe ML, Johnson RS, Sage EH (1994) SPARC is a source of copper-binding peptides that stimulate angiogenesis. J Cell Biol 125: 929-943

Marshall CJ (1995) Opportunities for pharmacological intervention in the ras pathway. Ann Oncol 6(Suppl 1): 63-67

Min C, Kirsch KH, Zhao Y, Jeay S, Palamakumbura AH, Trackman PC, Sonenshein GE (2007) The tumor suppressor activity of the lysyl oxidase propeptide reverses the invasive phenotype of Her-2/neu-driven breast cancer. Cancer Res 67: 1105-1112

Morgan EA, Forootan SS, Adamson J, Foster CS, Fujii H, Igarashi M, Beesley C, Smith PH, Ke Y (2008) Expression of cutaneous fatty acidbinding protein (C-FABP) in prostate cancer: potential prognostic marker and target for tumourigenicity suppression. Int J Oncol 32: $767-775$

Neubauer A, Dodge RK, George SL, Davey FR, Silver RT, Schiffer CA, Mayer RJ, Ball ED, Wurster-Hill D, Bloomfield CD (1994) Prognostic importance of mutations in the ras proto-oncogenes in de novo acute myeloid leukemia. Blood 83: $1603-1611$

Olson MF, Marais R (2000) Ras protein signalling. Semin Immunol 12: $63-73$

Orntoft TF, Wolf H (1998) Molecular alterations in bladder cancer. Urol Res 26: $223-233$

Payne SL, Fogelgren B, Hess AR, Seftor EA, Wiley EL, Fong SF, Csiszar K, Hendrix MJ, Kirschmann DA (2005) Lysyl oxidase regulates breast cancer cell migration and adhesion through a hydrogen peroxidemediated mechanism. Cancer Res 65: 11429-11436

Peng Z, Tang H, Wang X, Zhou C, Fan J, Wang L, Jia Z, Li Q, Le X, Wei D, Xie K (2008) Inhibition of the growth and metastasis of human colon cancer by restoration of RUNX3 expression in cancer cells. Int J Oncol 33: 979-984 
Pollina EA, Legesse-Miller A, Haley EM, Goodpaster T, Randolph-Habecker J, Coller HA (2008) Regulating the angiogenic balance in tissues. Cell Cycle 7: 2056-2070

Quackenbush J (2002) Microarray data normalization and transformation. Nat Genet 32(Suppl): 496-501

Recktenwald CV, Mendler S, Lichtenfels R, Kellner R, Seliger B (2007) Influence of Ki-ras-driven oncogenic transformation on the protein network of murine fibroblasts. Proteomics 7: 385-398

Roberts ML, Drosopoulos KG, Vasileiou I, Stricker M, Taoufik E, Maercker C, Guialis A, Alexis MN, Pintzas A (2006) Microarray analysis of the differential transformation mediated by Kirsten and Harvey Ras oncogenes in a human colorectal adenocarcinoma cell line. Int J Cancer 118: $616-627$

Shieh TM, Lin SC, Liu CJ, Chang SS, Ku TH, Chang KW (2007) Association of expression aberrances and genetic polymorphisms of lysyl oxidase with areca-associated oral tumorigenesis. Clin Cancer Res 13: 4378-4385

Slack JL, Parker MI, Robinson VR, Bornstein P (1992) Regulation of collagen I gene expression by ras. Mol Cell Biol 12: 4714-4723

Solana R, Romero J, Alonso C, Pena J (1992) MHC class I antigen expression is inversely related with tumor malignancy and ras oncogene product (p21ras) levels in human breast tumors. Invasion Metastasis 12: $210-217$

Tchernitsa OI, Sers C, Zuber J, Hinzmann B, Grips M, Schramme A, Lund P, Schwendel A, Rosenthal A, Schafer R (2004) Transcriptional basis of
KRAS oncogene-mediated cellular transformation in ovarian epithelial cells. Oncogene 23: $4536-4555$

Thomas EK, Nakamura M, Wienke D, Isacke CM, Pozzi A, Liang P (2005) Endo180 binds to the C-terminal region of type I collagen. J Biol Chem 280: $22596-22605$

Tusher VG, Tibshirani R, Chu G (2001) Significance analysis of microarrays applied to the ionizing radiation response. Proc Natl Acad Sci USA 98: $5116-5121$

Vasseur S, Malicet C, Calvo EL, Dagorn JC, Iovanna JL (2005) Gene expression profiling of tumours derived from rasV12/E1A-transformed mouse embryonic fibroblasts to identify genes required for tumour development. Mol Cancer 4: 4

Vasseur S, Malicet C, Calvo EL, Labrie C, Berthezene P, Dagorn JC, Iovanna JL (2003) Gene expression profiling by DNA microarray analysis in mouse embryonic fibroblasts transformed by rasV12 mutated protein and the E1A oncogene. Mol Cancer 2: 19

Wittinghofer F (1998) Ras signalling. Caught in the act of the switch-on. Nature 394: 317, $319-320$

Yuasa S, Onuki T, Mae M, Sasano H, Kei J, Nitta S (1994) (A case of ACTHreleasing lung carcinoid tumor presenting Cushing's syndrome). Nippon Kyobu Geka Gakkai Zasshi 42: $1963-1966$

Zuber J, Tchernitsa OI, Hinzmann B, Schmitz AC, Grips M, Hellriegel M, Sers C, Rosenthal A, Schafer R (2000) A genome-wide survey of RAS transformation targets. Nat Genet 24: 144-152 